\title{
Immediate Role of Two Yoga Based Mantra Recitation on Selective Attention in Undergraduate Students
} NAROTTAM KUMAR

\begin{abstract}
Aim of the present study was to evaluate the effect of Gayatri mantra recitation and Om recitation on selective attention as measured by color stroop. The study was performed on undergraduate students (Male=30) with age range of 18 to 30 years. All students were trained for reciting Gayatri mantra for 3 days. The baseline data were used. The participants participated in Gayatri mantra and Om recitation about $15 \mathrm{~min}$ for two consecutive days. The sequence of the session was assigned randomly to the participants. The attention was assessed using color stroop test before and immediately after each session. Within-group comparison showed that due to GM recitation and Om recitation, Stroop scores improved or significant improvement of Stroop scores in both groups ( $P<0.001$; Wilcoxon signed rank test). The percentage improvement of Stroop score was $16.16 \%$ after GM recitation whereas $9.26 \%$ after Om recitation. This pilot study shows that both Gayatri mantra and simply sitting led to improvement in attention, as measured by Stroop Task. But the influence of Gayatri mantra was significantly higher than Om recitation.
\end{abstract}

Key words: Gayatri mantra, Om Chanting, Selective Attention and Stroop Test

\section{GAYATRI MANTRA}

Gayatri mantra is highly potential mantra which is mentioned in Rigveda. Gayatri is the meter in which the mantra composed by brahmarñi viçvämitra. It is also called savitra mantra because it consist the deity sun or Savita. Gayatri mantra can be interpreted to invoke the Savita deity so it is called as savitra mantra (Harshananda, 2010). Gayatri mantra consist twenty four letters. Every letters of this mantra provide subtle conscious energy field and magnetic field around our body. Gayatri is kämadhenu that means which gives nectar like milk to everyone so it is called as kalpatarï which fulfils the desire of devotee (Acharya, 2000). The super natural impact of gayatri mantra is in the physical life due to the specific syllables of mantra. The mantra stimulates the subliminal power centers in the subtle body. The pressure on tongue, lips, vocal cords, palate and connecting region in the brain generated by continuous recitation of the 24 syllables of gayatri mantra creates a resonance in the nerve and nadis in the body. It creates the magnetic force or electromagnetic wave around the body that attracts the vital current of deity SUN (Acharya, 1998).

\section{Science of mantra and its effect}

Mantra becomes effectual upon yoga in samädhi because they direct and focus power through the individual mind and prana. Mantra is a Sanskrit word which is the combination of two roots. One roots means repetition, the other means freedom; repetition and freedom is the meaning of word mantra (Muktibodhananda, 2009). The word mantra which implies a specific structure of syllables and vowels and which work as an excellent spiritual tool to liberate the mind from ignorance, illusion, delusion. The sädhanä of mantra yoga is a special part of spiritual 
experiments on awakening of kundalini and realization of ultimate brahmaë through omkära (Pandya, 2009). The resonance sound of mantra operates as total energy system and mantra have the vibration pattern of their own. The some pattern of mantra stimulates a certain effect on the psychic nature of an individual. Every letter brings resonance in distinct part of the body, reciting the whole mantra generates a particular resonance pattern, the resonant wave from part to part in the body. This resonance pattern in the physical body produces very special effect on the body (Pradhan $\&$ Derle, 2012).

The science of mantra is very ancient and was practiced in all parts of the world; the mantra science was developed by ancient scientist (åñi) across the globe. Mantra vijnana is the science of cosmic powers of sound. Chanting of mantra is a meditative practice from the Indian tradition of spiritual practices. This ritualistic recitation helps to sublimate the mind to a single thought until it attains the state of samädhi. The Indian scriptures on yoga and spirituality mention a great deal on the basis of mantra vijnana and science of eternal syllables like Omkara, A-kara, U- kara, and Mkara. Mantra is the main practice that links yoga. Apart from the physical nervous system, our ancient scientist says that there are 72000 näòés (bundle of tubular vessels) as the part of psychic nervous system. Once the mantra is chanted, sound energy is generated and the vibration resonance of that energy is diffused and distributed into the nervous system. The yogic tradition states that through use of mantra one does can awaken the chakras and kundalini that is serpent power. Mantra is a word power which can be used for spiritual realization and desires (Acharya, 2008).

\section{Scientific literature review}

Scientific study also found that yoga mantra and religious chanting gives positive influence, vibration on physiological and psychological functions of the body. For instance, gayatri mantra chanting resulted in significant improvement on performance or attention in school children, the whole population was divided into two groups one is experimental group and second is control group. Subject consisted of 60 school students included boys 30 and girls 30 in the age range of 12-14 years, where they trained for Gayatri mantra chanting for five days. They were assessed on DLST immediately before and after two sessions GM chanting (10 min) and poem line chanting (10 min) with equal duration. Fifty percent of participants performed GM chanting and remaining of the PL recitation on day 6 (Pradhan \& Derle, 2012). Gayatri mantra chanting invokes the capacity to influence thinking compare to random thinking (Brondino et al., 2013). Previous studies reported that practice of Om chanting is effective in improving pulmonary function and vital capacity in healthy individual; 82 subjects were participated in this study divided into two study group (SG) consisting 41 participants and control group (CG) consisting 41 participants; SG practiced Om chanting per day for the period of 6 days for two weeks and CG did not asked to practice.

The result showed there is significant improvement in peak expiratory flow, forced expiratory flow, significant improvement in slow vital capacity (Nagendra \& Pradhan, 2010). A period of mental chanting 'OM' shows that there is significant reduction in heart rate and subtle changes in mental state indicated by reduction in 
skin resistance; Autonomic changes during 'OM' chanting, the autonomic and respiratory variable were studied in experienced mediators (experience ranging from five to twenty years). Each subject was studied in two types of session's meditation; one is experimental session with a period of mental chanting of 'OM' and control with a period of non-targeted thinking. The meditatiors showed significant reduction in heart rate during meditation (Telles, Nagarathna, \& Nagendra, 1995).The different types of Japanese prayer and Buddhist sutra showed different brain regional activation. The recitation of Nenbutsu prayer activates the prefrontal cortex and recitation of Buddhist sutra activates the left dorsolateral prefrontal cortex, right parietal cortex (Balasubramaniam, Telles, \& Doraiswamy, 2013). Control study the Vedic hymns chanting showed there is improvement in memory and sustained attention in teen ager school students. 60 students participated in this study in the age group of 13-15 years, the whole population divided into two group chanting experience group and non-chanting experience group. The sustained attention assessed by SLCT and memory was assessed by using delayed recall test (Ghaligi, 2006). Effect of harekrishna mahamantra on mental health indicators of participants. Five subjects were assessed during one week baseline and four week intervention chanting phase. The result showed that there is significant reduction in stress, depression and verbal aggressiveness (Wolf, 2000).

\section{Purpose of the present study}

Selective attention characterized by the process which allows an individual to select and focus on particular unit followed by suppressing distracting information. It is a skill that relevant for academic excellence. This particular skill represents an important focus in the field of education. Hence, the present study was planned to evaluate effect of GM recitation and Om recitation on selective attention in undergraduate students.

\section{MATERIALS AND METHODS}

\section{Participants}

30 healthy undergraduate students in the age group of 18-30 years (mean age: years) were recruited from S-vyasa Yoga University in Bangalore, Karnataka. The study was approved by ethics committee of S-vyasa. All participants are educated about the parameters, intervention and they have duly signed consent form previously to the study.

\section{Design of the study}

This was a self as control design having two session, Experimental session (Gayatri mantra) and control session (Om recitation). All the participants were trained in GM recitation and Om recitation for 3 days before the starting of the study. All participants were assessed on color Stroop test before and after a period of Gayatri mantra recitation and Om recitation. The two sets of measurement were taken on successive days. They are asked to sit comfortably on the floor in cross-legged posture with eyes closed. All participants were asked to recite Gayatri mantra for 15 minutes on day first and called same participants to practice Om chanting on day seacond. See Table 1. Assessment done in between September 2017 and November 2017. 
Table 1: Design of the study

\begin{tabular}{|c|c|c|}
\hline Baseline Assessment & Intervention & Post Assessment \\
\hline $\begin{array}{c}\text { Day '1' } \\
\text { Color Stroop scores }(\mathrm{n}=30)\end{array}$ & Gayatri mantra recitation for 15 & $\begin{array}{c}\text { Color Stroop scores } \\
(\mathrm{n}=30)\end{array}$ \\
& $\begin{array}{c}\text { mins } \\
\text { (Immediate effect) }\end{array}$ & \\
\hline Day '2' & Color Stroop scores \\
Color Stroop scores $(\mathrm{n}=30)$ & Om mantra recitation for 15 mins. \\
\end{tabular}

\section{Interventions:}

\section{Gayatri mantra}

In experimental session, the subjects were asked to recite Gayatri mantra about 15 minutes with sound. During the Gayatri mantra the eyes were closed and followed by traditional procedure of loud chanting.

Om bhurbhuvahsvah tatsviturvarenyam bhargo devasya dheemahi dhiyo yo nah pracodayat ||rig veda (3.62.10) \|

\section{Om mantra}

In control session, the same subjects were asked to recite Om loudly (Om...Om...Om) sound about 15 minutes.

\section{Assessments tool:}

\section{Color Stroop Test}

The stroop task consisted of a worksheet, which has 5 rows and 20 columns and randomly arranged different color words in rows and columns. Stroop effect is having three sets; it is the finding that naming the color of the second and third sets of the words is harder than the first sets of words.
Stroop has three differe-14.64 Td-2.966782t8(f)8.94808(20741( Uw rows an $2 \mathrm{mn} 0741$ ( )-(.)-7.00569( ) $96.83992 \mathrm{~W}=$ ord whicis writteans ree-14.64 Td(,)-7.00569( )-4.03508(r)-2.22611(e)-2.968 k4(d)-2.83 to say thef2or nfthe suects are asked t say thef-174.618(c)-2.92or nf-185.793(w)18. a., 200) he

1 by ohn0741( )-8(f852.222RC)-3.45101(i)-1.35585d20741( )-ey 2 
Figure 1: Sample of Color Stroop Task

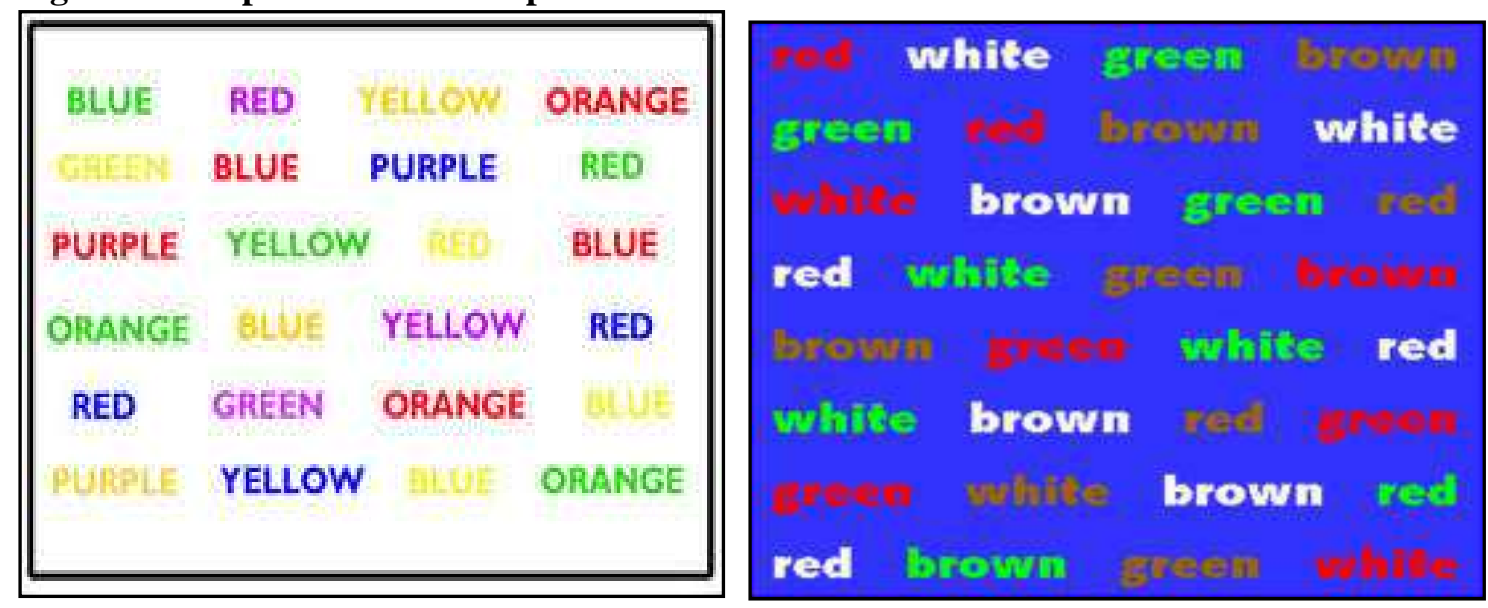

\section{RESULTS}

The baseline Stroop score was not found normally distributed by using Shapiro-wilk test $(\mathrm{P}<0.05)$. Within-group comparison showed that there is significant improvement in Stroop scores in both session $(\mathrm{P}<0.001$; Wilcoxon's Signed Rank test)

see Table 2. Stroop scores increased statistically in both sessions among the students. The percentage improvement of attention was $16.16 \%$ after Gayatri mantra recitation whereas $9.26 \%$ after Om recitation.

Table 2: Mean and standard deviation of STROOP Scores before and after Gayatri mantra recitation and $\mathrm{Om}$ recitation

\begin{tabular}{|l|l|l|l|l|l|}
\hline & Session & $\begin{array}{l}\text { Mean } \pm \text { SD } \\
\text { Pre }\end{array}$ & $\begin{array}{l}\text { Mean } \pm \text { SD } \\
\text { Post }\end{array}$ & $\mathbf{P}^{\alpha}$-Value & $\begin{array}{l}\% \\
\text { Change }\end{array}$ \\
\hline $\begin{array}{l}\text { STROOP } \\
\text { scores }\end{array}$ & GMR & $70.96 \pm 11.27$ & $82.43 \pm 10.24^{* * *}$ & 0.001 & 16.16 \\
\cline { 2 - 6 } & OMR & $73.4 \pm 13.35$ & $80.2 \pm 12.88^{* * *}$ & 0.001 & 9.26 \\
\hline
\end{tabular}

$\mathbf{G M R}=$ Gayatri mantra recitation; $\mathbf{O M R}=$ Om mantra recitation $\alpha$ Wilcoxon Signed Rank Test, $* * * \mathbf{P}<0.001$

\section{DISCUSSION}

There was significant improvement in Stroop score in both $\mathrm{Gm}$ and Om session. But analysis showed that there was better improvement in Gayatri mantra than the Om chanting session. Mantra is meant the frequent repetition which is rhythmic function of a meaningful word, name or expression. The power of such Christian mantras for personal transformation is discussed along with present significance of their rediscovery and use (Grassi, 1975). The prayer of Namo- Amida-Butsu (Nembutsu) activates the medial frontal gyrus, which is mainly related to mental concentration and visual spatial attention, similar to the areas activated by meditation. The task of reciting the sutra of Buddhist scriptures activates the left lateral middle frontal gyrus, the right angular 
gyrus, and the right marginal gyrus which are related to visual spatial attention (Shimomura et al., 2008).

Mantra is a free and open-source software package for object tracking. It is specifically designed to be used as a tool for response collection in psychological experiments; In Experiments 1 and 2 they validated the spatial and temporal precision of mantra in realistic experimental settings. In Experiments 3 and 4, we validated the spatial precision and accuracy of mantra more rigorously by tracking a computer controlled physical stimulus (Mathôt \& Theeuwes, 2011). Autonomic changes during 'Om' chanting, the autonomic and respiratory variable were studied in experienced meditation practicner (experience ranging from five to twenty years).Each subject was studied in two types of session's meditation; one is experimental session with a period of mental chanting of 'Om' and control with a period of non-targeted thinking. The result showed significant reduction in heart rate during meditation (Telles et al., 1995).

\section{Conclusion}

This pilot study suggests that Gayatri mantra recitation and Om recitation is effective yogabased mantra to improve selective attention in undergraduate students immediately after the practice. This study should be done with a large sample size and randomized controlled design using some strong tool.

NAROTTAM KUMAR, M.Sc., Research Associate and Yoga Instructor, Kautilya Entrepreneurship and Management Institute, Jain University, Bengaluru, India

\section{REFERENCES}

Acharya, S. S. (1998). Gayatri Sadhana Ki Vaigyanik Pristhabhumi (2nd ed.). Mumbai: Gayatri pariwar, Mumbai.

Acharya, S. S. (2000). Super Science of Gayatri. Haridwar: Yugantar Chetna Press, Shantikunj. Retrieved from www.awgp.org

Acharya, S. S. (2008). Eternity of sound and science of Mantra. Haridwar: Yug chetna press. Retrieved from www.awgp.org

Adleman, N. E., Menon, V., Blasey, C. M., White, C. D., Warsofsky, I. S., Glover, G. H., \& Reiss, A. L. (2002). A Developmental fMRI Study of the Stroop Color-Word Task. Neurolmage, 16(1), 61-75. https://doi.org/10.1006/ nimg.2001.1046

Balasubramaniam, M., Telles, S., \& Doraiswamy, P. M. (2013). Yoga on our minds: A systematic review of yoga for neuropsychiatric disorders. Frontiers in Psychiatry. https://doi.org/10.3389/fpsyt.2012.00117

Brondino, N., De Silvestri, A., Re, S., Lanati, N., Thiemann, P., Verna, A., ... Politi, P. (2013). A Systematic Review and Meta-Analysis of Ginkgo biloba in Neuropsychiatric Disorders: From Ancient Tradition to Modern-Day Medicine. EvidenceBased Complementary and Alternative Medicine, 2013(1), 111. https://doi.org/10.1155/2013/915691

Ghaligi, S. (2006). Effect of Vedic chanting on memory and sustained attention. Indian Journal of Traditional Knowledge, 5(4), 177-180.

Grassi, J. A. (1975). Christian mantras: the rediscovery and power of an ancient approach to inner Christian transformation. Worship, 49, 530-542.

Harshananda, S. (2010). Upanayana, Sandhya Vandana and Gayatri Mantra Japa. (3rd ed.). Chennai: Ramkrishna Math.

Mathôt, S., \& Theeuwes, J. (2011). Mantra: an open method for object and movement tracking. Behavior Research Methods. https://doi.org/10.3758/s13428-011-0105-9 
Muktibodhananda, S. (2009). Hatha Yoga Pradipika. Yoga vidya.com (3rd ed.). Munger: Yoga publication trust. Retrieved from www.bihayoganet.org

Nagendra, H., \& Pradhan, B. (2010). Immediate effect of two yoga-based relaxation techniques on attention in children. International Journal of Yoga, 3(2), 67. https://doi.org/10.4103/0973-6131.72632

Pandya, P. (2009). Science of Mantra. Haridwar: Brahma varchas research institute. Retrieved from www.awgp.org

Pradhan, B., \& Derle, S. (2012). Comparison of effect of Gayatri Mantra and Poem Chanting on Digit Letter Substitution Task. Ancient Science of Life, 32(2), 89. https://doi.org/10.4103/0257-7941.118540
Shimomura, T., Fujiki, M., Akiyoshi, J., Yoshida, T., Tabata, M., Kabasawa, H., \& Kobayashi, H. (2008). Functional brain mapping during recitation of Buddhist scriptures and repetition of the Namu Amida Butsu: a study in experienced Japanese monks. Turkish Neurosurgery, 18(2), 134-141.

Telles, S., Nagarathna, R., \& Nagendra, H. R. (1995). Autonomic changes during "OM" mediation. Indian Journal of Physiology and Pharmacology, 39(4), 418-420.

Wolf, D. B. (2000). Effects of the hare krsna maha mantra on stress, depression, and the three gunas. (spirituality, yoga). Dissertation Abstracts International: Section B: The Sciences and Engineering. https://doi.org/doi.org/10.5281/zenodo. 1117303 